Syntax Literate: Jurnal Ilmiah Indonesia p-ISSN: 2541-0849

e-ISSN: 2548-1398

Vol. 5, No. 9, September 2020

\title{
FORMULASI DAN EVALUASI FISIK SEDIAAN LOSION TABIR SURYA EKSTRAK KULIT BUAH MANGGA (MANGIFERA INDICA L.)
}

\section{Yenni Puspita Tanjung dan Owi Rowinda Lumanik}

Akademi Farmasi Bumi Siliwangi

Email: yennipuspitatanjung85@gmail.com dan owi15lumanik@gmail.com

\begin{abstract}
Mango peel (Mangifera indica L.) has a compound content of flavonoids that can be used as a sunscreen. This research purpose's to obtain a sunscreen lotion from Irwin mango peel extract, to find out which lotion formula meets the physical evaluation requirements, and to find out the effect of variations of Irwin mango peel extract on physical evaluation results. The sunscreen lotion formula is made with 3 variations of the concentration of mango Irwin fruit peel, namely F1 (0.3\%), F2 (0.5\%), and F3 (0.7\%). Physical evaluation of the sunscreen lotion formulations was carried out during 28 days of storage at room temperature based on the organoleptic evaluation, dispersion, homogeneity, $\mathrm{pH}$, viscosity, and the type of emulsion used. The results of this research indicate that sunscreen lotion preparations can be made from Irwin mango peel extract and sunscreen lotion mango peel extract preparations show F1, $F 2$, and F3 were qualified for the physical evaluation results which involved organoleptic, dispersion, homogeneity $\mathrm{pH}$, viscosity, and the type emulsion. Variations in the concentration of Irwin mango peel extract gave significantly different effect $(p<0.05)$ on the organoleptic evaluation and dispersion as well did not give a significant effect ( $p>0.05$ ) on the evaluation of $p H$, homogeneity, viscosity, and the type emulsion
\end{abstract}

Keywords: sunscreen lotion; mango skin extract (Mangifera indica L.); flavonoids

\section{Abstrak}

Kulit buah mangga (Mangifera indica L.) memiliki kandungan senyawa flavonoid yang dapat digunakan sebagai tabir surya. Penelitian ini bertujuan untuk memperoleh sediaan losion tabir surya dari ekstrak kulit buah mangga irwin dan mengetahui formula losion mana yang memenuhi syarat evaluasi fisik, serta untuk mengetahui pengaruh variasi ekstrak kulit buah mangga Irwin terhadap hasil evaluasi fisik. Formula losion tabir surya dibuat dengan 3 variasi konsentrasi ekstrak kulit buah mangga irwin yaitu F1 (0,3\%), F2 (0,5\%), dan F3 (0,7\%). Evaluasi fisik formulasi losion tabir surya yang telah dibuat dilakukan selama 28 hari penyimpanan pada suhu ruang meliputi evaluasi organoleptis, daya sebar, homogenitas, $\mathrm{pH}$, viskositas dan tipe emulsi yang digunakan. Hasil penelitian ini menunjukkan bahwa sediaan losion tabir surya dapat dibuat dari ekstrak kulit buah mangga irwin dan sediaan losion tabir surya ekstrak kulit buah mangga menunjukkan F1, F2, dan F3 memenuhi syarat hasil evaluasi fisik yang meliputi organoleptis, daya sebar, homogenitas, $\mathrm{pH}$, viskositas, dan tipe emulsi. Variasi konsentrasi ekstrak kulit buah mangga irwin memberikan hasil berbeda 
berpengaruh secara signifikan $(\mathrm{p}<0,05)$ terhadap evaluasi daya sebar serta tidak berpengaruh secara signifikan $(\mathrm{p}>0,05)$ terhadap evaluasi $\mathrm{pH}$ dan evaluasi viskositas.

Kata kunci: losion tabir surya; ekstrak kulit buah mangga (Mangifera indica L.); flavonoid

\section{Pendahuluan}

Pemaparan sinar matahari (sinar ultraviolet/sinar UV) yang berlebihan dapat menyebabkan eritema, hiperpigmentasi, bahkan sampai menyebabkan kanker kulit. Radiasi sinar UV yang paling berpotensi pigmentasi adalah sinar UV A (320 nm-400 $\mathrm{nm}$ ) dan yang menyebabkan terjadinya luka bakar (sunburn) dan kanker kulit adalah sinar UV B (290 nm-320 nm). Sedangkan sinar UV C (100 nm-290 nm) bersifat karsinogenik, namun sinar tersebut dapat disaring oleh lapisan ozon sehingga tidak sampai ke permukaan bumi (Arizona \& Zulkarnain, 2018) Pemaparan sinar ultraviolet secara kronik akan mengakibatkan perubahan struktur kulit dan stress oksidatif pada kulit (Sukma, 2018).

Kulit manusia sesungguhnya telah memiliki sistem perlindungan alamiah terhadap efek sinar matahari yang merugikan dengan cara penebalan stratum korneum dan pigmentasi kulit. Namun, tidak efektif untuk menahan sinar kontak yang berlebih. Berbagai upaya dilakukan untuk mengurangi dan mencegah timbulnya kerusakan seluler akibat radiasi UV. Oleh karena itu, diperlukan kosmetik pelindung kulit tambahan yaitu kosmesetikal tabir surya (Sukma, 2018).

Berdasarkan penelitian Joshi and Pawar diketahui bahwa kosmesetikal tabir surya dengan senyawa herbal telah menjadi tren modern dan semakin populer di bidang kecantikan karena efek sampingnya yang relatif sedikit. Salah satu senyawa herbal yang berpotensi digunakan sebagai tabir surya adalah kulit mangga (Joshi \& Pawar, 2015)

Limbah mangga berupa kulit memilki kandungan flavonoid yang merupakan senyawa fenolik dengan kapasitas antioksidan lebih besar dan aktivitas sebagai antikanker (Mukti, 2017). Menurut (Kim et al., 2010) bahwa kulit mangga memiliki kandungan flavonoid tiga kali lipat lebih banyak dibandingkan dengan daging buah mangga sebanyak 92,65 mg/g (Kim et al., 2010). Senyawa fenolik dapat berperan sebagai tabir surya karena antioksidan sebagai fotoprotektif untuk mencegah efek merugikan akibat radiasi UV (Sukma, 2018).

Hal ini didukung oleh (Panovska et al., 2005) yang mengungkapkan bahwa senyawa antioksidan merupakan suatu inhibitor yang digunakan untuk menghambat autooksidasi. Adanya kandungan flavonoid dengan aktivitas antioksidan memungkinkan kulit mangga dapat dibuat sebagai sediaan tabir surya (Panovska et al., 2005).

Bentuk sediaan tabir surya di pasaran dewasa ini banyak beredar dalam bentuk losion. Losion lebih mudah digunakan pada kulit karena konsistensinya tidak terlalu 
padat, sehingga dapat dengan cepat menyebar lebih merata pada permukaan kulit (Putri et al., 2019).

Berdasarkan latar belakang tersebut, perlu dilakukan penelitian formulasi losion tabir surya ekstrak kulit buah mangga irwin yang divariasikan konsentrasi dari ekstraknya.

\section{Metode Penelitian}

Jenis penelitian yang digunakan adalah penelitian eksperimental. Pada penelitian ini dilakukan beberapa tahapan antara lain formulasi sediaan losion tabir surya dari ekstrak kulit buah manga irwin. Dilakukan evaluasi fisik pada sediaan losion tabir surya meliputi organoleptis, daya sebar, homogenitas, $\mathrm{pH}$, viskositas dan tipe emulsi sediaan. Evaluasi fisik dilakukan selama penyimpanan 28 hari, yaitu hari ke 0, 1, 7, 14, 21, dan 28 pada suhu ruang $\left(25-30^{\circ} \mathrm{C}\right)$ (Zulkarnain \& Oktaviasari, 2017) .

\section{Tabel 1}

Formula Sediaan Losion Tabir Surya Ekstrak Kulit Buah Mangga Irwin

\begin{tabular}{|c|c|c|c|c|}
\hline \multirow{2}{*}{ Bahan } & \multicolumn{3}{|c|}{ Konsentrasi (\%) } & \multirow{2}{*}{ Kegunaan } \\
\hline & F1 & F2 & F3 & \\
\hline Ekstrak kulit buah mangga & 0,3 & 0,5 & 0,7 & Antioksidan \\
\hline Setil Alkohol & 5 & 5 & 5 & Pengemulsi, Emolien \\
\hline Parafin Cair & 4 & 4 & 4 & Emolien \\
\hline Asam Stearat & 5 & 5 & 5 & Pengemulsi \\
\hline Gliserin & 2,5 & 2,5 & 2,5 & Humektan \\
\hline Trietanolamin & 1 & 1 & 1 & Pengemulsi \\
\hline Metil paraben & 0,2 & 0,2 & 0,2 & Pengawet \\
\hline Propil paraben & 0,1 & 0,1 & 0,1 & Pengawet \\
\hline Aquades hingga & 100 & 100 & 100 & Pelarut \\
\hline Mango oil & 3 tetes & 3 tetes & 3 tetes & Pewangi \\
\hline
\end{tabular}

Pada penelitian ini dibuat losion tabir surya sebanyak 3 formula yang divariasikan konsentrasi ekstraknya yaitu $0,3 \%(\mathrm{~F} 1) ; 0,5 \%(\mathrm{~F} 2)$; dan $0,7 \%$ (F3). Variasi ini dilakukan untuk mengetahui apakah perbedaan konsentrasi ekstrak berpengaruh terhadap hasil evaluasi fisik yang meliputi organoleptis, homogenitas, daya sebar, $\mathrm{pH}$, viskositas, dan tipe emulsi yang digunakan.

Proses pembuatan losion tabir surya dilakukan dengan memisahkan bahan-bahan fase minyak dengan bahan-bahan fase air. Bahan fase minyak yaitu parrafin liquidum, asam stearat, dan setil alkohol berperan sebagai pengemulsi. Ketiga bahan tersebut dimasukkan ke dalam cawan penguap untuk dilebur pada waterbath dengan suhu $70^{\circ} \mathrm{C}$ karena ketiga bahan ini memiliki titik lebur pada suhu $70^{\circ} \mathrm{C}$. Bahan fase air terdiri dari gliserin sebagai humektan dan TEA sebagai pengemulsi. Kedua bahan ini dicampurkan dengan air panas di beaker glass pada suhu $70^{\circ} \mathrm{C}$. Pengawet yang digunakan dalam formulasi ini adalah kombinasi metil paraben dan propil paraben. Kombinasi pengawet ini dsilakukan karena dengan kombinasi maka dapat meningkatkan efek kerjanya untuk melindungi sediaan dari bakteri dan jamur (Rowe et al., 2009). Kedua bahan ini juga dilarutkan hingga larut dengan air panas di beaker glass pada suhu $70^{\circ} \mathrm{C}$. Fase minyak 
dan fase air dicampurkan pada suhu yang sama sambil diaduk hingga terbentuk basis losion. Prinsip basis losion umumnya sama seperti prinsip pembuatan krim dengan adanya reaksi saponifikasi (penyabunan) dari suatu asam lemak yang tinggi dengan suatu basa yang dikerjakan dalam suasana panas pada suhu $70^{\circ} \mathrm{C}$ (Butar-Butar, n.d.). Ekstrak kulit buah mangga irwin dilarutkan dengan aquades panas secukupnya dan ditambahkan dengan basis losion diaduk hingga homogen. Sediaan losion dimasukkan ke dalam wadah dan dilakukan evaluasi pada sediaan.

\section{A. Evaluasi Fisik Losion Tabir Surya}

1. Evaluasi Organoleptis

Uji organoleptis sediaan losion menggunakan panca indera dan parameter yang diamati adalah warna, bentuk dan bau (Putri et al., 2019).

2. Evaluasi Daya Sebar

Dilakukan dengan cara sampel diambil sebanyak 1 gram, diletakkan ditengah cawan petri dalam posisi terbalik, letakkan cawan petri yang lain di atas losion dalam posisi terbalik dan diberi beban 125 gram dengan rentang waktu 1-2 menit, lalu diukur diameter penyebarannya. Syarat diameter penyebaran daya sebar adalah $5 \mathrm{~cm}-7 \mathrm{~cm}$ (Garg, A, 2002).

3. Uji Homogenitas

Dioleskan sediaan losion di atas kaca objek, kemudian ditutup dengan penutup kaca objek. Amati ada atau tidaknya partikel kasar yang terdapat dalam sediaan (Damayanti et al., 2017).

4. Evaluasi $\mathrm{pH}$

Pengukuran $\mathrm{pH}$ sediaan losion menggunakan kertas $\mathrm{pH}$ universal. Pengukuran dilakukan secara langsung dengan mencelupkan kertas $\mathrm{pH}$ ke dalam losion dan disesuaikan hasil yang tertera pada warna $\mathrm{pH}$. Rentang $\mathrm{pH}$ yang diperbolehkan untuk sediaan tabir surya adalah 4,5-8,0 (Nasional, 1996).

5. Evaluasi Viskositas

Sebanyak 100 gram losion dimasukkan ke dalam beaker glass $250 \mathrm{ml}$ kemudian viskositasnya diukur menggunakan Viscometer Brokfield LV, kemudian diatur spindle no 4 dengan kecepatan $6 \mathrm{rpm}$ Viskositas yang diperbolehkan untuk sediaan tabir surya adalah 2000cp-50000cp (Rahman et al., 2013).

6. Evaluasi Tipe Emulsi

Menggunakan metilen biru yang diteteskan pada losion yang ada pada kaca objek. Jika tipe a/m (air dalam minyak) maka metilen biru akan bergerombol pada permukaan. Jika tipe m/a (minyak dalam air) maka zat warna akan melarut didalamnya dan bercampur merata (Sukma, 2018).

\section{B. Analisis Data Statistik}

Analisis data statistik ditentukan dengan uji normalitas data digunakan uji Shapiro Wilk dengan confidence interval 95\%. Bila nilai $\mathrm{p}>0,05$ maka data terdistribusi normal dan jika $\mathrm{p}<0,05$ maka data tidak terdistribusi normal. Data yang terdistribusi normal dilanjutkan menggunakan uji One Way ANOVA. Data 
yang tidak terdistribusi normal dilanjutkan menggunakan uji Kruskal Wallis. Nilai $\mathrm{p}>0,05$ menunjukkan tidak berpengaruh secara signifikan dan $\mathrm{p}<0,05$ menunjukkan berbeda berpengaruh signifikan (Meylina, 2018).

1. Alat

Neraca analitis, gelas kimia, kertas perkamen, spatel, pipet tetes, cawan porselen, penangas air (waterbath), $\mathrm{pH}$ universal, kaca objek, viscometer Brokfield LV, cawan petri, kaca arloji, termometer, mikroskop optic.

2. Bahan

Ekstrak kulit buah mangga irwin (Mangifera indica L.) (Lansida Herbal), Setil Alkohol (Fadjar Kimia), Parafin Cair (Fadjar Kimia), Gliserin (Fadjar Kimia), Asam Stearat (Fadjar Kimia), Trietanolamin (Fadjar Kimia), Propil paraben (Fadjar Kimia), Metil paraben (Fadjar Kimia), Aquades (Fadjar Kimia), Mango oil (Fadjar Kimia)

\section{Hasil dan Pembahasan}

\section{A. Hasil}

\section{Hasil Evaluasi Organoleptis}

\section{Tabel 2}

Hasil Evaluasi Organoleptis Sediaan Losion Tabir Surya

\begin{tabular}{clllllll}
\hline Formula & Organoleptis & Hari ke-0 & Hari ke-1 & Hari ke-7 & Hari ke-14 & Hari ke-21 & Hari ke-28 \\
\hline F1 & Bentuk & SP & SP & SP & SP & SP & SP \\
& Warna & KM & KM & KM & KM & KM & KM \\
& Bau & BKM & BKM & BKM & BKM & BKM & BKM \\
F2 & Bentuk & SP & SP & SP & SP & SP & SP \\
& Warna & KK & KK & KK & KK & KK & KK \\
& Bau & BK & BK & BK & BK & BK & BKM \\
F3 & Bentuk & SP & SP & SP & SP & SP & SP \\
& Warna & KK & KK & KK & KK & KK & KK \\
& Bau & BKM & BKM & BKM & BKM & BKM & BKM \\
\hline
\end{tabular}

Keterangan :

F1: Formula losion dengan ekstrak $0,3 \% ; \mathrm{F} 2$ : Formula losion dengan ekstrak 0,5\%;F3: Formula losion dengan ekstrak 0,7\%;SP : Semi Padat;KM : Kuning Muda;KK : Kuning Kecoklatan; BKM : Bau Khas Mangga.

\section{Hasil Evaluasi Daya Sebar}

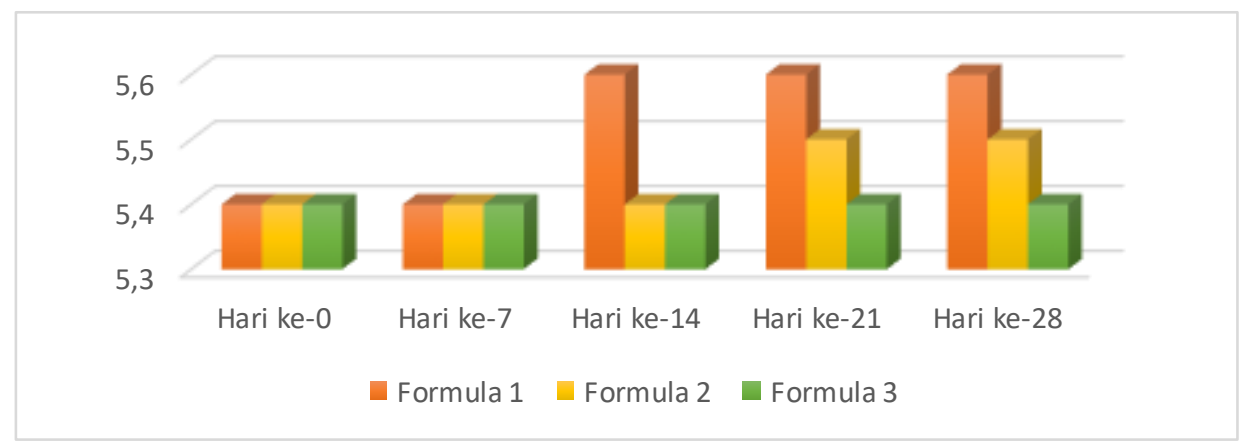

Gambar 1 
Formulasi Dan Evaluasi Fisik Sediaan Losion Tabir Surya Ekstrak Kulit Buah Mangga (Mangifera Indica L.)

\section{Hasil Evaluasi Homogenitas}

\section{Grafik Hasil Evaluasi Daya Sebar}

Tabel 3

Hasil Evaluasi Homogenitas Sediaan Losion Tabir Surya

\begin{tabular}{ccccccc}
\hline \multirow{2}{*}{ Formula } & \multicolumn{7}{c}{ Evaluasi Homogenitas (Hari ke-) } \\
\cline { 2 - 7 } & $\mathbf{0}$ & $\mathbf{1}$ & $\mathbf{7}$ & $\mathbf{1 4}$ & $\mathbf{2 1}$ & $\mathbf{2 8}$ \\
\hline F2 & + & + & + & + & + & + \\
F1 & + & + & + & + & + & + \\
F3 & + & + & + & + & + & + \\
\hline
\end{tabular}

Keterangan : (+) : Homogen; (-): Tidak Homogen

4. Hasil Evaluasi pH

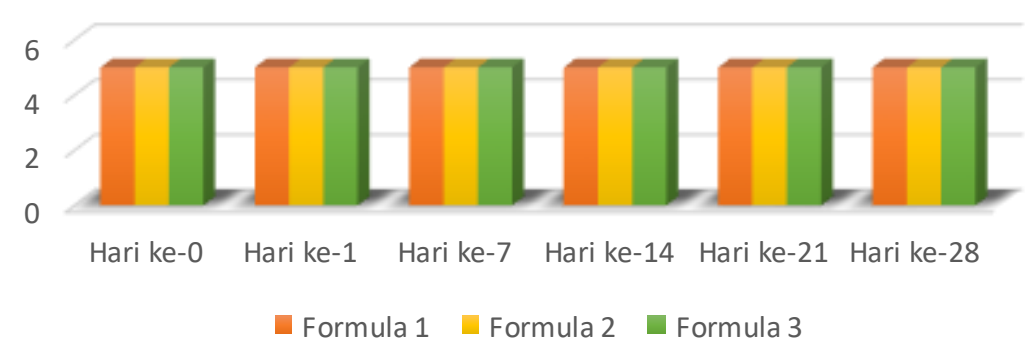

Gambar 2

Grafik Hasil Evaluasi pH

\section{Hasil Evaluasi Viskositas}

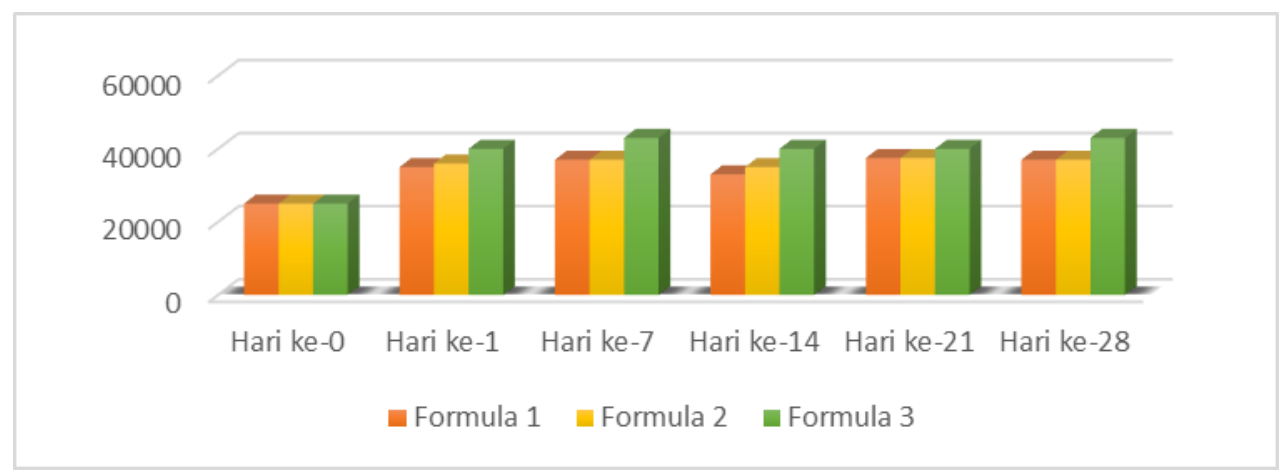

Gambar 3

Grafik Hasil Evaluasi Viskositas

6. Hasil Evaluasi Tipe Emulsi

Tabel 4

Hasil Evaluasi Tipe Emulsi Sediaan Losion Tabir Surya

\begin{tabular}{ccc}
\hline \multicolumn{3}{c}{ Tipe Emulsi } \\
\hline Formula & Awal (Hari ke-0) & Akhir (Setelah 28 hari penyimpanan) \\
\hline F1 & M/A & M/A \\
F2 & M/A & M/A \\
F3 & M/A & M/A \\
\hline
\end{tabular}




\section{B. Pembahasan}

Ekstrak kulit buah mangga irwin yang diperoleh ekstrak kental dengan warna coklat tua, bau khas, dan konsentrasi kental. Dari hasil skrinning fitokimia secara kualitatif membuktikan bahwa ekstrak kulit buah mangga irwin positif mengandung flavonoid. Dalam penelitian ini peneliti membandingkan evaluasi fisik dengan perbedaan konsentrasi ekstrak kulit buah mangga untuk masing-masing formula yaitu, 0,3\% untuk Formula I, 0,5\% untuk Formula II, dan 0,7\% untuk Formula III. . Sediaan losion tabir surya ekstrak kulit buah mangga dilakukan evaluasi fisik meliputi uji organoleptis, daya sebar, homogenitas, $\mathrm{pH}$, viskositas dan tipe emulsi pada suhu ruang $\left(25-30^{\circ} \mathrm{C}\right)$ (Zulkarnain \& Oktaviasari, 2017).

Hasil evaluasi organoleptis selama 28 hari (Tabel 2), ketiga formula memiliki perbedaan warna untuk F1 berwarna kuning muda sedangkan pada F2 dan F3 berwarna kuning kecoklatan. Pengaruh perbedaan warna pada sediaan diakibatkan oleh konsentrasi ekstrak yang ada di dalam sediaan losion tabir surya, warna ekstrak kulit buah mangga irwin memiliki warna coklat gelap. Semakin tinggi konsentrasi ekstrak dalam sediaan losion maka semakin gelap warna pada sediaan (Sukma, 2018).

Hasil evaluasi daya sebar selama 28 hari (Gambar 1) sediaan losion mengalami perubahan namun masih memenuhi persyaratan daya sebar sediaan losion. Perubahan daya sebar dipengaruhi oleh viskositas sediaan dimana angka fluktuatif yang dimiliki oleh viskositas berpengaruh terhadap daya sebarnya. Semakin rendah viskositas maka tahanan yang dimiliki pun rendah sehingga sediaan losion semakin mudah mengalir dan daya sebarnya meningkat (Nuralifah et al., 2019).

Hasil evaluasi homogenitas (Tabel 3) sediaan losion dapat membentuk sediaan yang homogen dimana tidak memiliki bintik-bintik atau butiran kasar (Daud et al., 2018).

Selanjutnya dilakukan evaluasi $\mathrm{pH}$ (Gambar 2) selama 28 hari penyimpanan nilai $\mathrm{pH}$ konsisten dengan angka $\mathrm{pH} 5$ dan sesuai dengan standar mutu sediaan losion 4,5- 8,0. Hal ini membuktikan sediaan losion relatif aman terhadap pemakaian kulit (Restika, 2017).

Pengukuran evaluasi viskositas (Gambar 3) sediaan losion mengalami perubahan pada nilai viskositas. Perubahan ini disebabkan oleh pengaruh wadah penyimpanan yang kurang kedap sehingga dapat menyebabkan sediaan losion tabir surya menyerap air dari luar, perubahan suhu dan kondisi tempat penyimpanan seperti kelembaban udara (Sopyan et al., 2016).

Hasil evaluasi tipe emulsi (Tabel 4) sediaan losion tabir suya memiliki tipe emulsi losion m/a. Tipe emulsi M/A sesuai dengan diharapkan untuk sediaan losion karena memiliki banyak keuntungan diantaranya mudah dibilas dengan air dan tidak lengket sehingga memberikan kenyamanan pada pemakai (Daud et al., 2018). 
Data yang diperoleh terlebih dahulu dilakukan uji normalitas data menggunakan uji Shapiro Wilk. Hasil menunjukkan bahwa data tidak terdistribusi normal dimana $\mathrm{p}<0,05$. Pengujian selanjutnya dilakukan dengan uji Kruskal Wallis dan didapatkan hasil sediaan losion tabir surya dengan variasi konsentrasi ekstrak kulit buah mangga irwin memberikan hasil berbeda berpengaruh secara signifikan $(\mathrm{p}<0,05)$ terhadap evaluasi organoleptis dan daya sebar serta tidak berpengaruh secara signifikan $(\mathrm{p}>0,05)$ terhadap evaluasi $\mathrm{pH}$, homogenitas, viskositas dan tipe emulsi.

\section{Kesimpulan}

Ekstrak kulit buah mangga irwin (Mangifera indica L.) dapat diformulasikan dalam bentuk sediaan losion tabir surya. Formula losion tabir surya ekstrak kulit buah mangga irwin dengan variasi konsentrasi ekstrak kulit buah mangga irwin yang memenuhi syarat evaluasi fisik adalah F1 (0,3\%), F2 (0,5\%), dan F3 (0,7\%). Variasi konsentrasi ekstrak kulit buah mangga irwin pada losion tabir surya memberikan hasil berbeda berpengaruh secara signifikan $(\mathrm{p}<0,05)$ terhadap evaluasi organoleptis dan daya sebar. Serta tidak berpengaruh secara signifikan $(\mathrm{p}>0,05)$ terhadap evaluasi $\mathrm{pH}$, homogenitas, viskositas, dan tipe emulsi. 


\section{BIBILIOGRAFI}

Arizona, M., \& Zulkarnain, A. K. (2018). Optimasi Formula dan Uji Aktivitas Secara In Vitro Lotion O/W Ekstrak Etanolik Rimpang Temu Mangga (Curcuma Mangga Val. dan van Zijp) sebagai Tabir Surya. Majalah Farmaseutik, 14(1).

Butar-Butar, E. (2011). Pembuatan Dan Uji Sediaan Krim Hidrokortison. Fakultas Farmasi Universitas Sumatera Utara Medan

Damayanti, R. H., Meylina, L., \& Rusli, R. (2017). Formulasi Sediaan Lotion Tabir Surya Ekstrak Daun Cempedak (Artocarpus champeden Spreng). Proceeding of Mulawarman Pharmaceuticals Conferences, 6, 167-172.

Daud, N. S., Musdalipah, M., \& Idayati, I. (2018). Optimasi Formula Lotion Tabir Surya Ekstrak Kulit Buah Naga Super Merah (Hylocereus costaricensis) Menggunakan Metode Desain D-Optimal. Jurnal Sains Farmasi \& Klinis, 5(2), $72-77$.

Garg, A, D. (2002). Aggarwal, S., Garg, A, K., Sigla, Pharmaceutical Technology. Mary Clark, North America.

Joshi, L. S., \& Pawar, H. A. (2015). Herbal cosmetics and cosmeceuticals: An overview. Nat Prod Chem Res, 3(2), 170.

Kim, H., Moon, J. Y., Kim, H., Lee, D.-S., Cho, M., Choi, H.-K., Kim, Y. S., Mosaddik, A., \& Cho, S. K. (2010). Antioxidant and antiproliferative activities of mango (Mangifera indica L.) flesh and peel. Food Chemistry, 121(2), 429-436.

Meylina, K. (2018). .Optimasi dan Asam Stearat Pada Lotion Tabir Surya Ekstrak Etanol Kelopak Bunga Rosella (Hibiscus sabdariffa L.) Dengan Metode Desain Faktorial. Skripsi Program Studi Farmasi. Universitas Sanata Dharma. hal 8.

Mukti, G. W. (2017). Peningkatan Nilai Tambah Limbah Kulit Mangga Melalui Pelatihan Pembuatan Keripik Dan Manisan Kulit Mangga. Jurnal Pengabdian Kepada Masyarakat, 1(3).

Nasional, B. S. (1996). Sediaan Tabir Surya, Badan Standardisasi Nasional, Jakarta. SNI 16-4399-1996.

Nuralifah, N., Armadany, F. I., Parawansah, P., \& Pratiwi, A. (2019). Uji Aktivitas Antibakteri Sediaan Krim Anti Jerawat Ekstrak Etanol Terpurifikasi Daun Sirih (Piper betle L.) dengan Basis Vanishing Cream Terhadap Propionibacterium acne. Pharmauho: Jurnal Farmasi, Sains, Dan Kesehatan, 4(2).

Panovska, T. K., Kulevanova, S., \& Stenova, M. (2005). In Vitro Antioxidant of Some Teucrium Spesies (Lamiaceae). Journol Acta Pharmachology, 55(2).

Putri, Y. D., Kartamihardja, H., \& Lisna, I. (2019). Formulasi dan Evaluasi Losion 
Tabir Surya Ekstrak Daun Stevia (Stevia rebaudiana Bertoni M). Jurnal Sains Farmasi \& Klinis, 6(1), 32-36.

Rahman, A. G., Astuti, I. Y., \& Dhiani, B. A. (2013). Formulasi lotion ekstrak rimpang bangle (Zingiber purpureum roxb) dengan variasi konsentrasi trietanolamin sebagai emulgator dan uji iritasinya. PHARMACY: Jurnal Farmasi Indonesia (Pharmaceutical Journal of Indonesia), 10(1).

Restika, E. (2017). Formulasi dan Penentuan Potensi Tabir Surya dari Krim Ekstrak Metanol Umbi Ubi Kelapa Ungu (Dioscorea alata var purpurea). Universitas Islam Negeri Alauddin Makassar.

Rowe, R. C., Sheskey, P., \& Quinn, M. (2009). Handbook of pharmaceutical excipients. Libros Digitales-Pharmaceutical Press.

Sopyan, I. I., Apriana, R. A., \& dolih Gozali, D. (2016). Formulasi Sediaan Losio Dari Esktrak Kulit Buah Delima (Punica Granatum L.) Sebagai Tabir Surya. Farmaka, 14(1), 43-58.

Sukma, Y. C. (2018). Formulasi sediaan tabir surya mikroemulsi ekstrak kulit buah Nanas (Ananas comosus L) dan uji in vitro nilai sun protection factor (SPF). Universitas Islam Negeri Maulana Malik Ibrahim.

Zulkarnain, A. K., \& Oktaviasari, L. (2017). Formulasi dan Uji Stabilitas Fisik Sediaan Lotion O/W Pati Kentang (Solanum Tuberosum L.) Serta Aktivitasnya Sebagai Tabir Surya. Majalah Farmaseutik, 13(1). 